\title{
INSTALLATION AND PRELIMINARY RESULTS FROM A SMALL APERTURE SEISMIC ARRAY IN TRIPOLI, GREECE
}

\author{
Pirli M., Voulgaris N., Alexopoulos J. and Makropoulos K.
}

Department of Geophysics-Geothermics, Faculty of Geology, University of Athens, PO Box 157-

84,Panepistimioupoli - Zographou, Athens, pirli@geol.uoa.gr, voulgaris@geol.uoa.gr, jalexopoulos@geol.uoa.gr, kmacrop@geol.uoa.gr

\begin{abstract}
A small aperture seismic array was installed by the University of Athens, in the area of Tripoli, Greece, on July $16^{\text {th }} 2003$, in order to test the performance of seismic array processing in the area of Greece and assess its contribution to earthquake location, especially in offshore areas not azimuthally covered by the existing, conventional seismological networks.

The array consists of four three-component seismological stations, one of them in the middle of a small, almost equilateral triangle, formed by the deployment of the other three stations. Despite the fact that array siting is a compromise of array installation criteria, equipment safety and logistics, the test character of the experiment can be served successfully. The array transfer function depicts good azimuthal coverage nonetheless the existence of side-lobes and a rather wide main lobe is characteristic of spatial aliasing and low resolution in the two-dimensional wavenumber domain. The resolvable wavenumber passband of the array permits the determination of most of the common seismic body wave phases $\left(P_{n}, P_{g}, S_{n}, S_{g}\right.$, etc.) for local and regional events in the area of Greece.

Location of recorded events was performed using slowness and backazimuth data, calculated by $\mathrm{f}-\mathrm{k}$ analysis of the seismic waveforms. Preliminary results have been compared to epicentres calculated by the Geodynamic Institute of the National Observatory of Athens. Although some differences are observed, these are not significant and location results as well as overall array performance can be improved by array calibration and travel-time, azimuth and slowness correction calculations
\end{abstract}

\section{INTRODUCTION}

Seismic arrays have been developed mainly after the late 1950s as a means for monitoring compliance to a future treaty for the suspension of nuclear tests. During the 1960 s many large aperture seismic arrays were installed worldwide, such as LASA and NORSAR, aiming to monitor teleseismic events (Douglas 1981). Later on, interest was transferred to small aperture arrays, such as NORESS and GERESS that could monitor events in the local, regional and near-teleseismic field (Harjes 1990, Mykkeltveit et al. 1990). Arrays were preferred to single three-component stations owing to their ability to enhance the signal to noise ratio due to a signal delay-and-sum procedure called "beamforming". Advances in informatics and signal processing provided new, more sophisticated algorithms, ability to store and handle large volumes of array data and contributed in the development of automatic procedures for on-line data processing and event location. Nowadays, seismic arrays are widely used on a global scale and hold an important role in the seismic verification and monitoring of the Comprehensive Test Ban Treaty (CTBT).

A seismic array is defined as a group of closely spaced seismological stations with one of the sensors being assigned the role of a reference site, operating as a common time base. Data processing techniques and restrictions in geometry, spatial extent and data quality, applied by a required high coherency level across its aperture, discriminate an array from a conventional seismological network (Schweitzer et al. 2002). The most important criteria for the founding of a seismic array are common geological setting for all array sites, taking advantage of outcropping bedrock 
when possible, lack of elevation differences between array elements, inter-element spacing satisfying destructive noise interference and aperture small enough when compared to epicentral distance to support a plane wavefront assumption for the arriving signal. As far as data processing is concerned, slowness and azimuth values of the arriving plane wave phases are calculated applying beamforming either in the time or frequency-wavenumber domain.

Mostly due to their ability in enhancing signal to noise ratio, seismic arrays are used widely in global monitoring and discrimination of earthquakes and explosions. Other applications include seismic wave propagation research focused on tomography, earth structure, propagation of regional phases, scattering of seismic waves, coda analysis and surface waves, regional seismicity and seismotectonics as well as volcanic activity monitoring.

The Seismological Laboratory of the University of Athens installed a small aperture seismic array, consisting of four stations, at a military Air-force Training Unit near Tripoli, Greece, on July $16^{\text {th }}$, 2003. The objective is to assess the performance of array signal processing for local and regional earthquakes in the geologically complex and seismotectonically active area of Greece. Seismic arrays could be considered as an alternative and supplementary solution to the exclusive use of conventional seismological station networks, in terms of monitoring and locating seismic events, especially in offshore areas of high seismicity rates, not azimuthally covered by the existing networks, such as the external part of the Hellenic Arc. Enhanced event location in border regions results in improved seismic hazard estimation and advanced precision in seismic source zone determination. Furthermore, satisfactory array performance at regional distances would create possibilities for seismicity monitoring in the broader Aegean Sea and Balkan region and 3-D structural investigation of the broader area.

Complex geology and morphology of the area of Tripoli as well as practicality issues such as equipment safety and logistics applied constraints to array design. However, the test character of the array experiment could be successfully served despite the fact that array design criteria could not be satisfied entirely.

Array response assessment and first, preliminary results indicated a satisfactory performance in detecting and locating local and regional events. The existing array geometry responded well regarding signal coherency and noise correlation, permitting the use of broadband $f-k$ analysis algorithms (Kværna \& Ringdal 1986) for the estimation of slowness and backazimuth of the seismic phases determined. Resulting values along with associated phase onsets were used to locate events, comparing locations derived from the application of different velocity models, both regional and local. Overall array performance in terms of detection and preliminary location was compared to that of the National Seismic Network operated by the Geodynamic Institute of the National Observatory of Athens (Papanastassiou 1989), results being quite encouraging in respect to seismic array contribution in seismicity monitoring in Greece.

\section{ARRAY SITING}

\subsection{Array location}

The Tripoli Seismic Array (TRISAR) is located at $22.40892^{\circ} \mathrm{E}$ longitude and $37.53963^{\circ} \mathrm{N}$ latitude, at the 124 Military Air-force Basic Training Unit outside Tripoli, Greece. The broader area of Tripoli consists of a plateau surrounded by Mainalon Mt., Lyrkion Mt., Artemission Mt. and Parnonas Mt. The plateau includes several sedimentary basins. The array site is located in the Tripoli basin whose natural boundaries are Karakovouni Mt., Karakovrahos Mt., Koutroufi Mt. and Agiovouni Mt. to the east, the straight formed by Karakovouni Mt. and Prof. Ilias rise to the north, Mainalon Mt. to the west and the old Athens-Tripoli national road to the south. The basin extends over $30 \mathrm{~km}^{2}$ and has a mean elevation of $645 \mathrm{~m}$. Elevation differences across the deployment are less than $2 \mathrm{~m}$, therefore no corrections for station elevation need to be introduced for the array elements. The main reason advocating for the installation of the seismic array at the particular site was the fact that extended geophysical research had been conducted in the area previously by Alexopoulos (1998), providing a detailed knowledge of the local geological setting.

The broader area of Tripoli is characterized by the existence of geological formations belonging to the geotectonic units of Tripoli and Pindos as well as post-alpine formations. 
The array site is located on quaternary deposits. Vertical electrical soundings performed in the region (Alexopoulos 1998) revealed a thickness of approximately $95 \mathrm{~m}$. Quaternary sediments overlay flysch deposits of the geotectonic unit of Pindos that form the alpine basement of the area. At the depth of approximately $250 \mathrm{~m}$, transient layers between flysch formations and limestones were found, consisting of marly limestones.

Installing the array at the extension of the air-stripe of the 124 Military Air-force Basic Training Unit, close to the town of Tripoli, served practicality reasons such as ease of access and equipment safety. It is therefore expected that some noise due to human activities will be present in the seismic records. Except for any activity at the Training Unit, which however is limited as the airport is not used, sources of noise in the broader seismic array area consist of traffic, both in the populated areas and the highway, and agricultural activities. Nonetheless, these sources are located at a distance greater than $1 \mathrm{~km}$ far from the array site. In particular, Tripoli, the largest populated area in the district, is $3 \mathrm{~km}$ away, the shortest distance to the highway is $1 \mathrm{~km}$ and areas of organized agricultural and industrial activity are further than $3 \mathrm{~km}$ away. The immediate surroundings of the airport of the Training Unit are arid land containing neither populated areas nor areas of any kind of human activity.

\subsection{Array design}

When designing a seismic array, several parameters need to be taken into consideration, in order to achieve a satisfactory performance. Array location, geometry, number of elements and aperture determine accuracy in slowness estimation, whereas inter-element spacing and maximum recordable frequency control the minimum wavelength that can be resolved by the array. Number of elements is also important in relation to signal to noise ratio enhancement, defining the overall theoretical gain that can be accomplished.

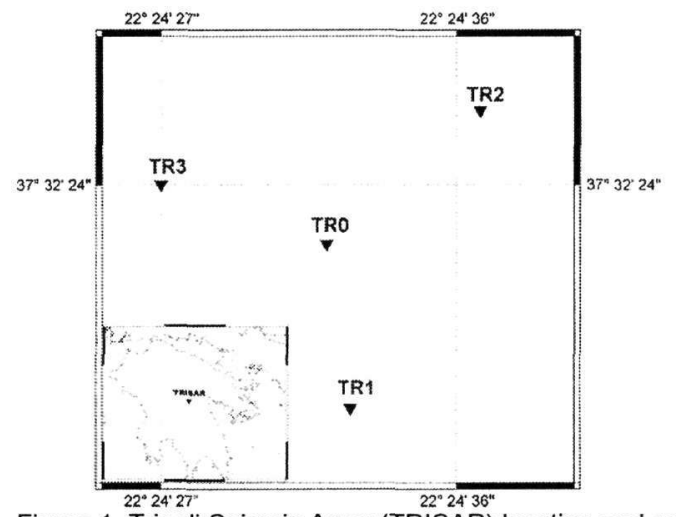

Figure 1. Tripoli Seismic Array (TRISAR) location and geometry.

The Tripoli Seismic Array consists of four seismological stations, the three of them forming an almost equilateral triangle with a side of approximately $240 \mathrm{~m}$ and the fourth element sited in the middle of the deployment (Fig. 1). Inter-element spacing is approximately $140 \mathrm{~m}$. Information concerning each array site is provided in table 1.

Table 1. Tripoli Seismic Array site information.

\begin{tabular}{lrrrrr}
\hline Site & Latitude $\left(^{\circ}\right)$ & Longitude $\left({ }^{\circ}\right)$ & Elevation $(\mathbf{m})$ & Geological formation & Sensor \\
\hline TR0 & 37.5396 & 22.4089 & 676 & Quaternary deposits & CMG-40T \\
TR1 & 37.5385 & 22.4091 & 677 & Quaternary deposits & CMG-1Hz \\
TR2 & 37.5405 & 22.4102 & 678 & Quaternary deposits & CMG-1Hz \\
TR3 & 37.5400 & 22.4075 & 676 & Quaternary deposits & CMG-1 Hz \\
\hline
\end{tabular}


Each array site consists of a three-component, digital, portable seismograph equipped with a RefTek 72A-07/G/ND DAS unit, a Güralp seismometer and an external 4GB hard disk for data storage. Timing is controlled by a GPS unit and power supply is provided by solar panels and batteries. The element in the middle of the deployment is assigned the role of the reference station (TRO) and is equipped with a broadband CMG-40T seismometer, of a 60 seconds period, while all other sites (TR1, TR2, TR3) are short-period stations with seismometers of $1 \mathrm{~Hz}$ natural frequency. Continuous trigger mode and a sampling rate of 125 samples per second are applied to the data. The latter are organized into data-streams, each of them containing three channels with the same gain, corresponding to the vertical and horizontal components. Figure 2 depicts instrumentation configuration for one of the array elements.

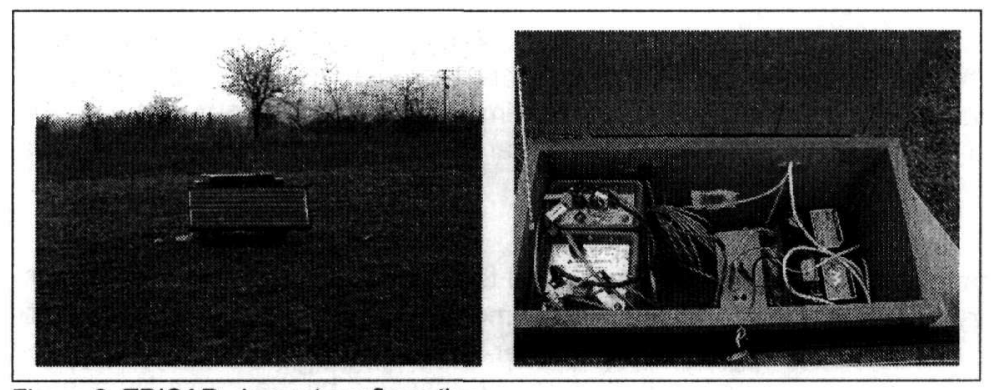

Figure 2. TRISAR element configuration.

Equipment safety and logistics applied significant constraints to array design, both in relation to resolution and precision in azimuth and slowness estimation.

A larger aperture would increase the overall array ability to resolve small wavenumber values however this was not possible as it would compromise safety, equipment being exposed to theft and damage outside the Training Unit's guarded area. Moreover, a larger aperture retaining the same number of array elements would increase inter-element distance. This might result in loss of signal coherency and constructive noise interference. Adding elements would compromise our economical planning for maintenance.

Another important point is the lack of a common time base due to logistics. However, this is not regarded as a serious drawback in terms of accuracy as timing precision provided by the GPS unit, synchronizing every half hour, at each element is satisfactory taking into consideration the sampling interval of the data.

\section{ARRAY TRANSFER FUNCTION}

Array response was evaluated by calculating its transfer function for several frequencies in the range of interest. The array pattern for frequencies of $1 \mathrm{~Hz}$ and $20 \mathrm{~Hz}$ is depicted here (Fig. 3). Array pattern is equivalent to the array's wavenumber response as a spatiotemporal filter to a monochromatic, plane wave of frequency equal to $1 \mathrm{~Hz}$. Actual seismic signals are formed by wavelets characterized by different frequency ranges therefore the array transfer function should be calculated for the frequencies of interest. The transfer function determines array performance in terms of resolution and aliasing in the two-dimensional wavenumber domain. Resolution is reciprocal to the main lobe's width, which depends on array aperture. Existence of side-lobes, repetitions of the main lobe, characterized by amplitude close or equal to that of the main lobe but for higher wavenumber values, indicates spatial aliasing in the wavenumber domain. The chromatic scale corresponds to power density function decrease in $\mathrm{dB}$ and is a measure of signal coherency loss in the referred frequency band (Rost 2000, Schweitzer et al. 2002, Wang 2002).

The circular shape of the main lobe and the symmetrical repetition of the whole pattern reveal perfect azimuthal coverage, which was however expected due to the triangular layout of the array. The main lobe is rather wide, an effect of small aperture. This fact denotes a relative lack of accuracy in slowness and azimuth estimation. Another important feature is the appearance of side- 
lobes, representing spatial aliasing effects. This observation applies for frequencies greater than 10 $\mathrm{Hz}$, implying that no spatial aliasing exists for lower frequencies in the slowness range of interest.

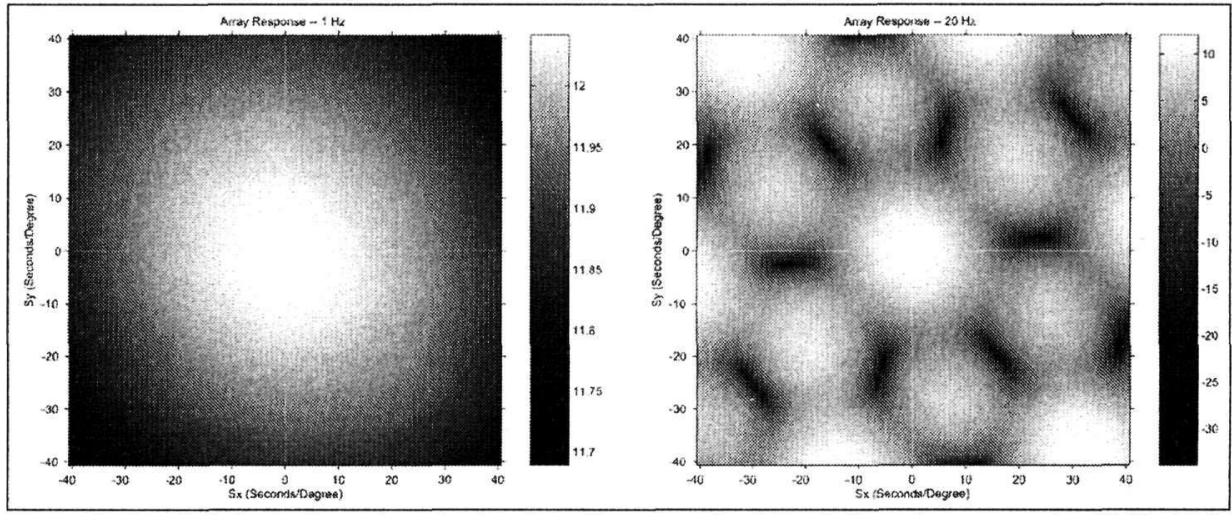

Figure 3. Tripoli Seismic Array transfer function. Response for $1 \mathrm{~Hz}$ (left) and response for $20 \mathrm{~Hz}$ (right). Scale in $\mathrm{dB}$.

The ability of the array to distinguish between various seismic phases with different wavenumber values can be measured using the 3dB-drop criterion (Johnson \& Dudgeon 1993, Wang 2002). The radius of the contour line of the $3 \mathrm{~dB}$-drop from the maximum value is equal to the minimum wavenumber that can be resolved by the array, whereas the half distance between the centre of the main lobe and the centre of the closest side-lobe defines the maximum resolvable wavenumber. In the present case the minimum wavenumber value is equal to $9.05 \mathrm{rad} / \mathrm{km}$ and the maximum to $28.277 \mathrm{rad} / \mathrm{km}$. These values correspond to slowness values of $0.072 \mathrm{sec} / \mathrm{km}$ and $0.225 \mathrm{sec} / \mathrm{km} \mathrm{re-}$ spectively. It is therefore obvious that the Tripoli Seismic Array cannot distinguish surface wave phases that are characterized by slowness values larger that $0.225 \mathrm{sec} / \mathrm{km}$ however is capable of determining the most common body wave phases for local and regional distances (e.g. $\mathrm{Pn}, \mathrm{Pg}, \mathrm{Sn}$, Sg etc.).

\section{PRELIMINARY RESULTS}

\subsection{Data set description}

During its first four months of operation Tripoli Seismic Array has recorded more than 4000 seismic events from the broader area of Greece, 1059 of which had their focal parameters calculated by the Geodynamic Institute of the National Observatory of Athens (NOA). Frequencywavenumber analysis results, epicentres and statistics presented in this paper include the first ten days of array operation (108 events) and 63 selected events from the remaining time interval. The selection criteria satisfied practicality matters, such as a large epicentral distance range and good azimuthal coverage. 100 of these events were also located by the National Observatory of Athens.

\subsection{Processing}

Processing of the seismic data recorded by TRISAR consists of two parts. The first part deals with data preparation procedures and the second with actual array data processing.

\subsubsection{Preprocessing}

Seismic records were downloaded from the RefTek hard disks in SEGY format and were converted to SAC-files in order to introduce array parameters (station coordinates, elevation and offsets) into the file headers and remove the instrument response (Goldstein, 1998). For events with focal parameters calculated by NOA (www.gein.noa.gr), event coordinates were also introduced into the headers and horizontal component rotation was performed. For events of unknown origin, no rotation was performed during the preliminary processing, nevertheless comparison of solutions with and without component rotation showed no significant differences in azimuth and slowness estimation. 
Owing to the fact that array signal processing was to be conducted with MATSEIS (Hart 2003), SAC-files were converted to CSS3.0 Flatfiles, a database being formed for each seismic event. Each database includes waveforms for each component, information for each waveform, site information and origin information for the specific event when available.

\subsubsection{Array signal processing}

Before applying array signal processing techniques, the spatial coherence level of the used waveforms needs to be known, as coherence levels determine the processing technique to be used for slowness and azimuth calculation. So, spatial coherence is calculated both for P- and S- waves for the frequency range that is to be used for $\mathrm{f}-\mathrm{k}$ analysis (Capon 1969, Capon 1970).

Standard array data processing includes application of broadband $f-k$ analysis techniques (Kværna \& Ringdal 1986) on narrow time windows, corresponding to seismic phases of interest. Appropriate bandpass filters were applied to the waveforms prior to the $f-k$ filter, in order to achieve more stable solutions. Selected time windows were very narrow, approximately 2 seconds, not including any noise in order to avoid noise correlation effects. The filters applied were only slightly broader in range compared to the $\mathrm{f}-\mathrm{k}$ filter, as this technique provides more stable results in backazimuth estimation. In particular, for $\mathrm{P}$-wave phases a $3^{\text {rd }}$-order Butterworth filter with cutoff frequencies at 2 and $10 \mathrm{~Hz}$ was applied to the vertical component and a similar filter with frequencies of 0.5 and $7 \mathrm{~Hz}$ for S-wave phases, to the horizontal components.

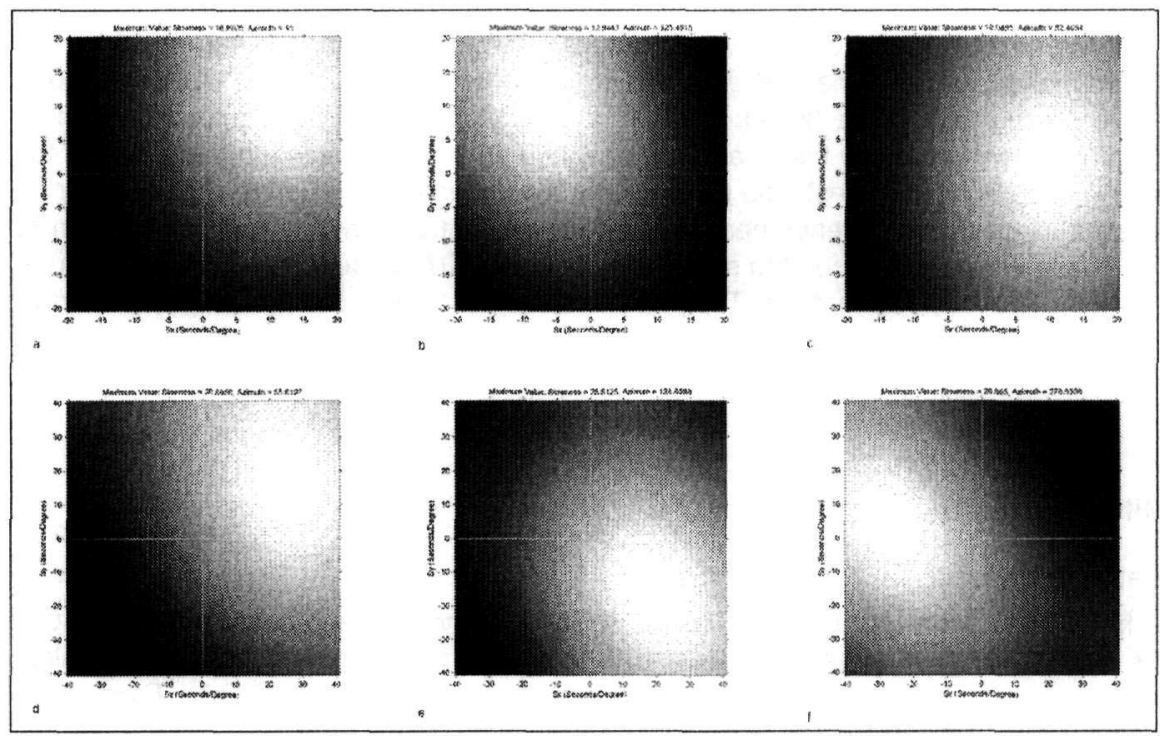

Figure 4. Frequency-wavenumber analysis examples. a) $\mathrm{Pg}$ phase from Attiki, b) Pn phase from Lefkada island, c) Pn phase from western Turkey, d) $\mathrm{Lg}$ phase from Korinthia, e) Sn phase from Karpathos island and f) $\mathrm{Sg}$ phase from Kyparissiakos gulf.

The $\mathrm{f}-\mathrm{k}$ filter was thus applied to the selected time windows for the frequency range of 3 to $8 \mathrm{~Hz}$ for $\mathrm{P}$-waves and 1.5 to $5 \mathrm{~Hz}$ for S-waves. Figure 4 displays $\mathrm{f}-\mathrm{k}$ plots for several seismic events, both for $\mathrm{P}$ - and $\mathrm{S}$-wave phases. Pattern similarity to that of the array transfer function for $1 \mathrm{~Hz}$ denotes high coherence level of the used waveforms.

In cases where there is a very low signal to noise ratio, beamforming is applied to the waveforms. Gain by beamforming equals the square root of array number of elements, so in the case of TRISAR gain is merely equal to 2 , nevertheless some enhancement is observed that allows more precise arrival times determination. Furthermore, the inclusion of the beam in $f-k$ analysis application provides more stable solutions.

Whenever waveform coherence level is insufficient for broadband $\mathrm{f}-\mathrm{k}$ analysis and beamforming application, incoherent beamforming is applied (Schweitzer et al. 2002). Incoherent beams are formed by the summation of the STA time series of each array element filtered trace. 


\subsection{Location of seismic events}

Calculated slowness and azimuth results for each phase, along with the corresponding arrival time, are the data needed to locate seismic events. Used phases are identified with the assistance of appropriate travel-time tables. The velocity model used is a regional model for the broader area of Greece and western Asia Minor, depicted in table 2 (Sweeney \& Walter 1998). Thus, identified phases and associated information are introduced into HYPOSAT algorithm (Schweitzer 2001a, Schweitzer 2003), to simultaneously invert travel times, azimuth and slowness values to calculate hypocentre coordinates and the associated errors. Location accuracy is expressed by error ellipses, calculated for either $95 \%$ or $68 \%$ confidence level and actual horizontal errors in degrees. These values are dependent on uncertainties in azimuth and used onset times. Uncertainty in onset times is a function of onset reading errors and travel-time errors, while azimuth resolution is dependent on slowness resolution, which is determined by the array transfer function.

Except for the regional model, several velocity models (Drakatos et al. 1998, Haslinger et al. 1999, Drakatos et al. 2003) of a more local character were tested for locations at the corresponding areas, however results with the regional model were found to be more stable.

Table 2. Velocity model used in event location (Sweeney \& Walter 1998).

\begin{tabular}{lrrr}
\hline Layer & Depth $(\mathbf{k m})$ & P-velocity $(\mathbf{k m} / \mathbf{s})$ & S-velocity $\mathbf{( k m / s )}$ \\
\hline 1 & 0.000 & 2.500 & 1.100 \\
2 & 1.000 & 4.000 & 2.100 \\
3 & 3.500 & 6.000 & 3.400 \\
4 & 13.500 & 6.600 & 3.700 \\
5 & 24.500 & 7.200 & 4.000 \\
6 & 34.000 & 7.900 & 4.460 \\
\hline
\end{tabular}

Focal depth cannot be determined by the use of single array data, except for circumstances when phases characteristic of depth are available. Moreover, information concerning focal depth may be provided by performing joint locations, both with array and single station data.

Figure 5 depicts horizontal errors in seismic event location for the first ten days of array operation, calculated by the HYPOSAT algorithm. For the largest number of events, horizontal error is less than $0.05^{\circ}$, revealing satisfactory accuracy in terms of location for such a small array aperture.

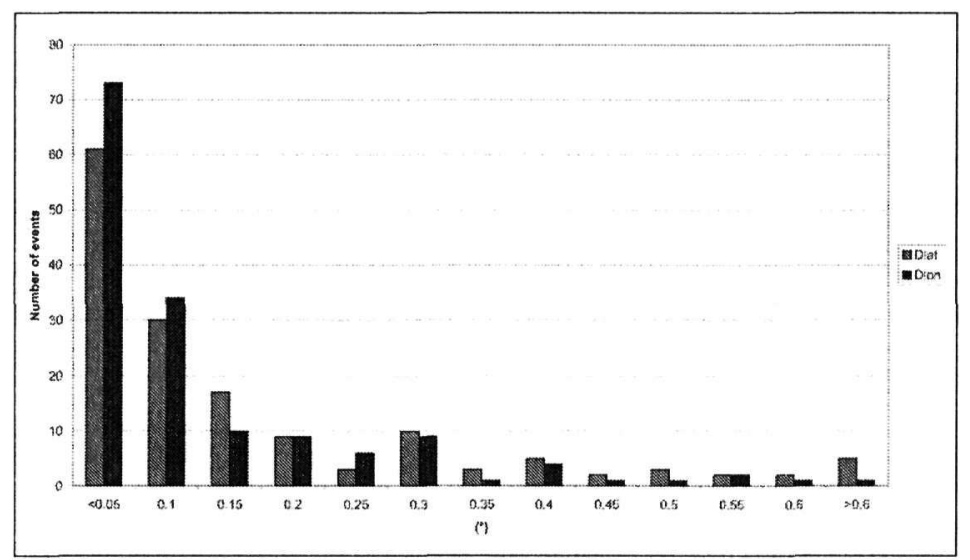

Figure 5. Horizontal error in event location calculated by the HYPOSAT algorithm.

Event locations are displayed on the topographic map of figure 6. Located events cover a wide range of azimuth values and epicentral distances. The large number of events that is located at the Peloponnese and the Gulf of Corinth was predictable, owing to the fact that this specific distance range corresponds to the optimum performance distance range for TRISAR, both in terms of de- 
tectability and data coherence. Spatial coherence highest levels are observed in the distance range between 60 and $180 \mathrm{~km}$ from the array, while small array aperture introduces large uncertainty levels in azimuth determination beyond $200 \mathrm{~km}$ from the array.

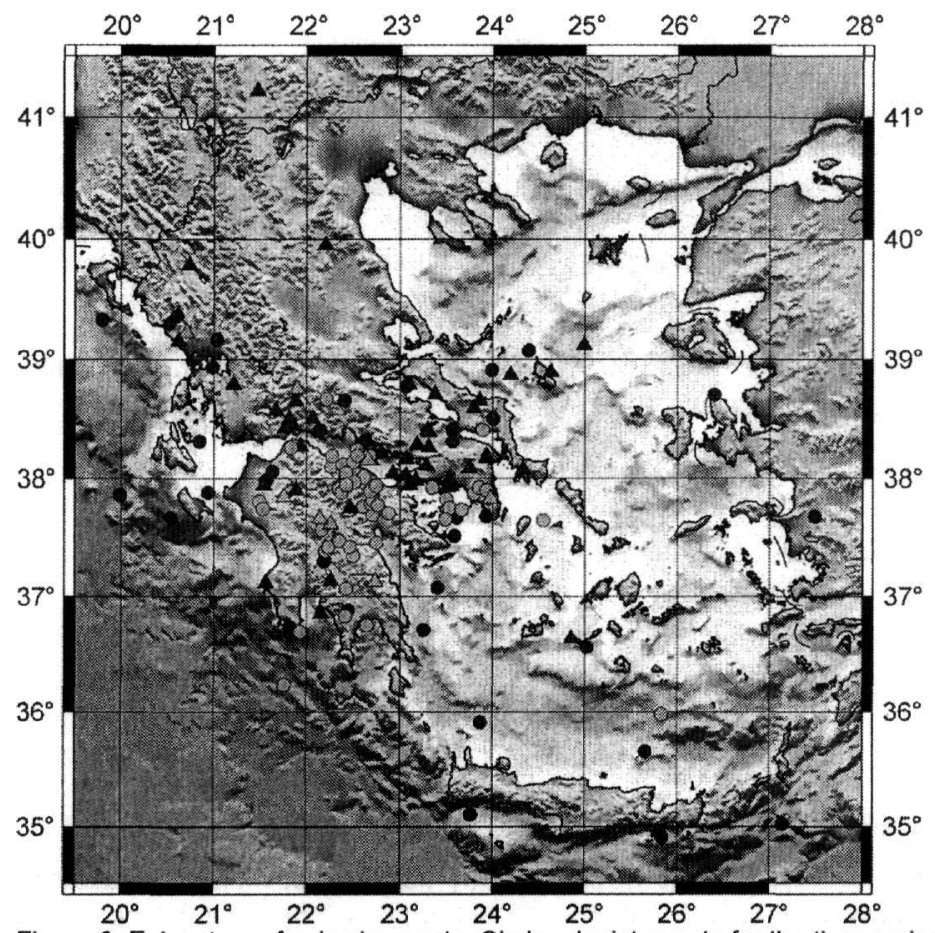

Figure 6. Epicentres of seismic events. Circles depict events for the time period 16/07/03-26/07/03 and triangles for 27/07/03-02/02/04. Light colour describes events located only by TRISAR, while dark colour depicts events located both by TRISAR and NOA.

\section{DISCUSSION}

Overall array performance concerns its ability to record, identify and accurately locate earthquakes. Array performance regarding location accuracy as a function of epicentral distance depends mainly on array aperture, so the very small dimensions of TRISAR restrict severely its ability to accurately locate events from large epicentral distances. Locations can be accomplished (Fig. 6) but there is a quite large bias in azimuth value estimation.

Accuracy in slowness estimation is controlled by the number of array elements that determine array resolution as a wavenumber filter. Small number of elements restricts array ability to distinguish between seismic phases of close wavenumber values, which reflects on identification of used phases and finally on event location accuracy. The use of very narrow time windows and the exclusion of noise can improve $\mathrm{f}-\mathrm{k}$ analysis results nevertheless it is advisable to use the most prominent seismic phases in the records.

Array location results are compared, when possible, to those of NOA in order to evaluate location accuracy. A comparison between latitude and longitude estimated by TRISAR and NOA is displayed by the $x-y$ scatter diagrams of figure 7 . Both diagrams depict a good linear relationship between the two solutions, independent variable coefficient being approximately unity, with scattering being slightly higher for latitude. For small epicentral distance ranges, the relationship is characterized by good linearity, while any large misfit values are observed for larger epicentral distances, mainly beyond $250 \mathrm{~km}$. This fact verifies the range of optimum distance in terms of array performance, determined also by high waveform coherence levels. 


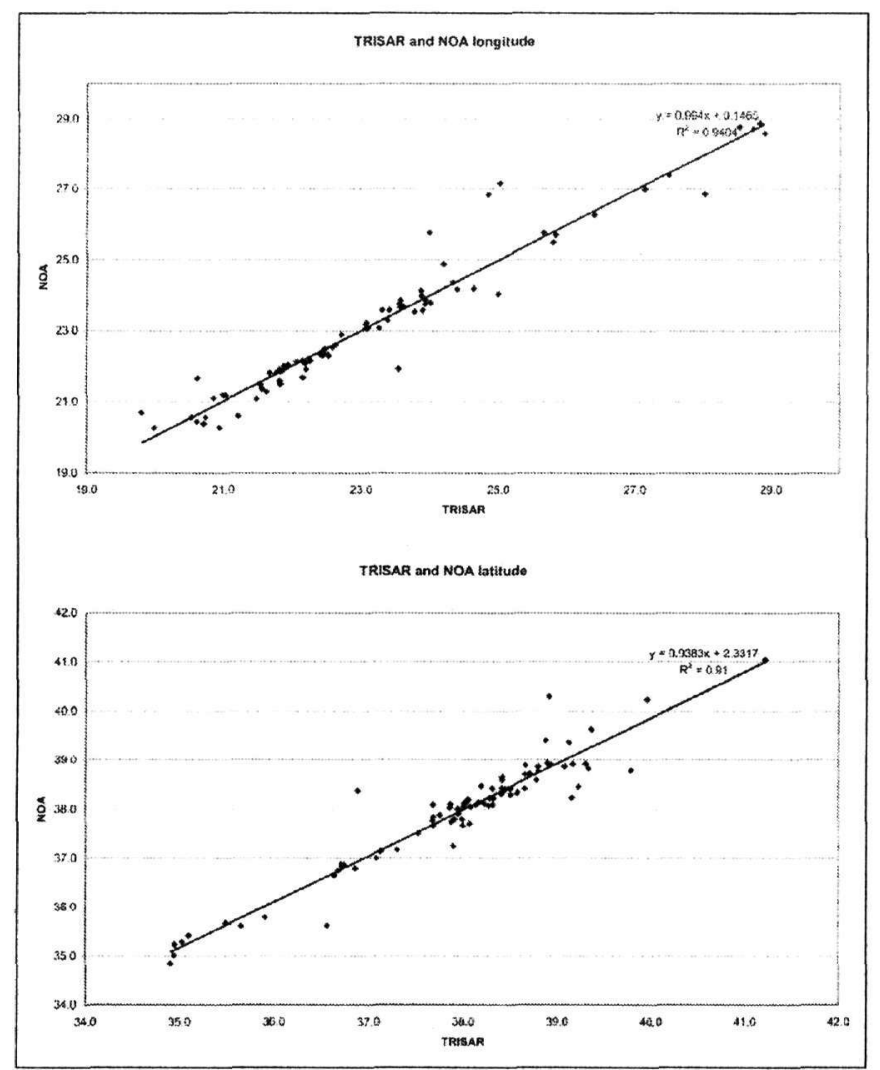

Figure 7. Scatter-diagrams for longitude (above) and latitude (below) calculated by TRISAR and NOA.

The larger number of seismic events detected and located by TRISAR, compared to the number of earthquakes located by NOA, attests the advantage of array operation supplementary to conventional seismological network performance, regarding seismic activity monitoring. This is very important especially for areas of poor azimuthal coverage by the conventional networks and in particular in the optimum array performance distance range. The case of the Lefkada Island aftershock sequence is a characteristic example, as TRISAR has recorded more than 250 events during the first 36 hours of the aftershock sequence.

\section{CONCLUSIONS}

Processing and results of the first data from Tripoli Seismic Array depict satisfactory overall array performance both in terms of event detection and location. Data cover a very wide range of azimuth values and epicentral distances, with no obvious dependence of waveform coherence on azimuth distribution. The array has the ability to locate earthquakes in the epicentral distance range between 40 and $600 \mathrm{~km}$, the optimum performance distance range being between 60 and $180 \mathrm{~km}$.

Location results are characterized by sufficient accuracy, especially at distances less than 250 $\mathrm{km}$, as shown by calculated errors in event location and error ellipses dimensions. Comparison of TRISAR location results to those of the National Observatory of Athens presents some differences that can be decreased by calibrating the array (Myers et al. 2002, Tibuleac \& Herrin 1997) as well as calculating travel-time, azimuth and slowness corrections for areas where abundant data are available (Ram \& Yadav 1984, Schweitzer 2001b).

Array advantage over conventional networks for offshore areas of poor azimuthal coverage is quite clear, despite any restrictions imposed on array design and the test character of the project. This fact denotes that a seismic array with increased abilities compared to the existing TRISAR 
configuration can make an important contribution in event location supplementary to that of existing seismological networks.

Reconfiguration of the existing array, by increasing the number of elements and investigating the possibility of aperture increase will enhance array performance in greater epicentral distances, in order to provide better coverage for the western and southwestern Hellenic Arc.

\section{ACKNOWLEDGEMENTS}

The authors would like to acknowledge funding provided by the University of Athens Special Account for Research Grants through program 70/4/4173.

\section{REFERENCES}

Alexopoulos, J., 1998. A contribution to the investigation of the hydrogeological regime of the Tripoli plateau, using geophysical methods, PhD Thesis, Athens, University of Athens, 275pp (in Greek).

Capon, J., 1969. High-resolution frequency-wavenumber spectrum analysis, Proc. IEEE, 57, 1408-1418.

Capon, J., 1970. Application of signal detection and estimation theory to large array seismology, Proc. IEEE, 58, 170-181.

Douglas, A., 1981. Seismic source identification, a review of past and present research efforts. In E. S. Husebye and S. Mykkeltveit (edts), Identification of seismic sources - earthquake or underground explosions, 1-48, Dordrecht, Holland, Reidel Publishing Co.

Drakatos, G., Papanastassiou, D., Voulgaris, N., and Stavrakakis, G., 1998. Observations on the 3-D crustal velocity structure in the Kozani-Grevena (NW Greece) area, J. Geodynamics, 26(2-4), 341-351.

Drakatos, G., Voulgaris, N., Pirli, M., Melis, N., and Karakostas, B., 2003. 3-D crustal velocity structure in northwestern Greece, accepted at PAGEOPH.

Goldstein, P., 1998. SAC2000-Seismic Analysis Code user's manual, Livermore, Lawrence Livermore National Laboratory.

Harjes, H.-P., 1990. Design and siting of a new regional array in Central Europe, BSSA, 80(6), 1801-1817.

Hart, D., 2003. MatSeis user's manual, version 1.7, Sandia National Laboratories, $121 \mathrm{pp}$.

Haslinger, F., Kissling, E., Ansorge J., Hatzfeld, D., Papadimitriou, E., Karakostas, V., Makropoulos, K., Kahle, H.-G., and Peter, Y., 1999. 3D crustal structure from local earthquake tomography around the Gulf of Arta (Ionian region, NW Greece), Tectonophysics, 304, 201-218.

Johnson, D. H., and Dudgeon, D. E., 1993. Array signal processing, Englewood Cliffs, New Jersey, PrenticeHall Inc., 512pp.

Kværna, T., and Ringdal, F., 1986. Stability of various f-k estimation techniques, NORSAR Semiannual Technical Summary, 1-87/88, 29-40.

Myers, S., Flanagan, M., Pasyanos, M., Walter, W., Vincent, P., and Schultz, C., 2002: Location calibration in Western Eurasia and North Africa: Ground truth, improved earth models, Bayesian kriging, regional analysis, location algorithms, array calibration, and validation, 24th Seismic Research Review - Nuclear Explosion Monitoring: Innovation and Integration, 351-360.

Mykkeltveit, S., Ringdal, F., Kværna, T., and Alewine R. W., 1990. Application of regional arrays in seismic verification research, $B S S A, 80(6), 1777-1800$.

Papanastassiou, D., K., 1989. Detectability and focal parameter estimation accuracy of N.O.A. seismological networks, PhD Thesis, Athens, University of Athens, 225pp (in Greek).

Ram, A., and Yadav, L., 1984. Structural corrections for slowness and azimuth of seismic signals arriving at Gauribidanur array, BSSA, 74(1), 97-105.

Rost, S., 2000. A study of the Earth's upper mantle discontinuities in the Pacific using a short-period array, PhD Dissertation, Göttingen, Georg-August-Univerzität zu Göttingen.

Schweitzer, J., 2001a. HYPOSAT - An enhanced routine to locate seismic events, PAGEOPH, 158, $277-289$.

Schweitzer, J., 2001b. Slowness corrections - one way to improve IDC products, PAGEOPH, 158, 375-396.

Schweitzer, J., 2003. HYPOSAT User Manual, Kjeller, Norway, NORSAR, 15pp.

Schweitzer, J., Fyen, J., Mykkeltveit, S., and Kværna, T., 2002. Seismic arrays. In P. Bormann (edt), New Manual of Seismological Observatory Practice, Potsdam, $51 \mathrm{pp}$.

Sweeney, J. J., and Walter, W. R., 1998. Preliminary definition of geophysical regions in the Middle East and North Africa, Lawrence Livermore National Laboratory Informal Report, UCRL-ID-132899, 40pp.

Tibuleac, I., and Herrin, E., 1997: Calibration studies at TXAR, Seismol. Res. Lett., 68, 353-365.

Wang, J., 2002. A scheme for initial beam deployment for the International Monitoring System arrays, PAGEOPH, 159, 1005-1020. 